\title{
Does multicomponent physical exercise with simultaneous cognitive training boost cognitive performance in older adults? A 6-month rando- mized controlled trial with a I-year follow-up
}

\author{
This article was published in the following Dove Press journal: \\ Clinical Interventions in Aging \\ 17 August 2015 \\ Number of times this article has been viewed
}

\author{
Patrick Eggenberger ${ }^{1}$ \\ Vera Schumacher ${ }^{2,3}$ \\ Marius Angst ${ }^{1}$ \\ Nathan Theill ${ }^{4,5}$ \\ Eling $D$ de Bruin ${ }^{1,6,7}$ \\ 'Institute of Human Movement \\ Sciences and Sport, Department \\ of Health Sciences and Technology, \\ ETH Zurich, ${ }^{2}$ Department of \\ Gerontopsychology and Gerontology, \\ "University Research Priority Program \\ "Dynamics of Healthy Aging", \\ University of Zurich, Zurich, ${ }^{4}$ Division \\ of Psychiatry Research, University \\ of Zurich, Schlieren, ${ }^{5}$ Center for \\ Gerontology, University of Zurich, \\ Zurich, Switzerland; ${ }^{6}$ CAPHRI School \\ for Public Health and Primary Care, \\ Department of Epidemiology, ${ }^{7}$ Centre \\ for Evidence Based Physiotherapy, \\ Maastricht University, Maastricht, the \\ Netherlands
}

Background: Cognitive impairment is a health problem that concerns almost every second elderly person. Physical and cognitive training have differential positive effects on cognition, but have been rarely applied in combination. This study evaluates synergistic effects of multicomponent physical exercise complemented with novel simultaneous cognitive training on cognition in older adults. We hypothesized that simultaneous cognitive-physical components would add training specific cognitive benefits compared to exclusively physical training.

Methods: Seniors, older than 70 years, without cognitive impairment, were randomly assigned to either: 1) virtual reality video game dancing (DANCE), 2) treadmill walking with simultaneous verbal memory training (MEMORY), or 3) treadmill walking (PHYS). Each program was complemented with strength and balance exercises. Two 1-hour training sessions per week over 6 months were applied. Cognitive performance was assessed at baseline, after 3 and 6 months, and at 1-year follow-up. Multiple regression analyses with planned comparisons were calculated. Results: Eighty-nine participants were randomized to the three groups initially, 71 completed the training, while 47 were available at 1-year follow-up. Advantages of the simultaneous cognitive-physical programs were found in two dimensions of executive function. "Shifting attention" showed a timexintervention interaction in favor of DANCE/MEMORY versus PHYS $(F[2,68]=1.95$, trend $P=0.075, r=0.17)$; and "working memory" showed a timexintervention interaction in favor of DANCE versus $\operatorname{MEMORY}\left(F[1,136]=2.71\right.$, trend $\left.P=0.051, R^{2}=0.006\right)$. Performance improvements in executive functions, long-term visual memory (episodic memory), and processing speed were maintained at follow-up in all groups.

Conclusion: Particular executive functions benefit from simultaneous cognitive-physical training compared to exclusively physical multicomponent training. Cognitive-physical training programs may counteract widespread cognitive impairments in the elderly.

Keywords: elderly, executive function, transfer, cognitive impairment, dance, video game

\section{Introduction}

A decrease in cognitive performance in old age is predominant in most individuals. This was confirmed by a large Italian epidemiological study demonstrating that agingassociated cognitive decline has a prevalence rate of $28 \%$ for people from 65 years to 84 years. ${ }^{1}$ Additionally, another $17 \%$ of this Italian population $(n=4,785)$ showed objective evidence of cognitive decline without cognitive complaints, which add up to a total of $45 \%$ of people showing some kind of cognitive impairment without dementia. Since cognitive decline potentially threatens independence and quality of life for older adults, prevention and treatment of cognitive impairment in the elderly
Correspondence: Patrick Eggenberger Institute of Human Movement Sciences and Sport, ETH Zurich, WolfgangPaulistrasse 27, HIT J 32, CH-8093 Zurich, Switzerland

Tel +4I 4463240 I8

Fax $+4 \mid 44632$ I| 42

Email patrick.eggenberger@hest.ethz.ch 
has assumed increasing importance. ${ }^{2}$ Two factors that may positively affect cognition in the elderly are physical activity and cognitive training.

Research has pointed out recently that physical activity may be relevant for healthy brain aging and may protect from cognitive decline and dementia. ${ }^{3-7}$ Most physical intervention studies that focused on adaptations in cognitive performance, brain function, or brain structure, applied aerobic type exercise. Two meta-analytic studies reported that aerobic exercise is effective in increasing cognitive performance, in general, and executive function in particular. ${ }^{89}$ More recent studies also found that strength and coordination training may positively affect cognitive abilities. ${ }^{10,11}$ Voelcker-Rehage et al ${ }^{11}$ demonstrated training specific functional plasticity in the brain based on functional magnetic resonance imaging data. Thereby, aerobic training increased activation in the sensorimotor network and coordination training led to a higher activation of the visuospatial network, ${ }^{11}$ whereas strength training changed the hemodynamic activity of brain regions associated with response inhibition processes. ${ }^{12}$

Cognitive training studies have often shown highly task specific effects. ${ }^{13-17}$ More widespread transfer effects were found when different cognitive abilities were combined in complex interventions or lifestyle changes. ${ }^{18}$ Nevertheless, effects were often small, while aerobic training elicited both broad transfer and relatively large effects. ${ }^{18}$ These findings led to the assumption that not only the combination of different cognitive abilities but also the combination of cognitive and physical training improves cognitive performance in old age to a greater extent than the training of an isolated ability. ${ }^{5,718-22}$ Therefore, more and more studies pursue exactly this goal by administering a combined cognitivephysical training approach.

Some studies applied the physical and cognitive training sessions in a sequential manner, ${ }^{23-26}$ whereas others performed the physical and cognitive training units simultaneously. ${ }^{27-30}$ An advantage of simultaneous training designs might be that they include dual tasking and switching attention between the cognitive and physical activity. For instance, Theill et $\mathrm{al}^{27}$ investigated the effects of simultaneous memory training and treadmill walking and revealed benefits in cognitive-motor dual-task walking compared to a single cognitive training and a passive control group. Virtual reality video game dancing represents a novel mode of simultaneous cognitive-physical training and has been applied by Pichierri et al. ${ }^{28,29}$ Intervention groups demonstrated increased cognitive-motor dualtask performance in a stepping accuracy task ${ }^{28}$ or during fast walking, ${ }^{29}$ respectively. Nonetheless, interpretation of the existing studies on combined cognitive-physical training is often limited due to small sample sizes, ${ }^{24,26,28,29}$ inconsistent training exposures between intervention groups, ${ }^{23-25,28,29}$ or the lack of reference groups with only physical training. ${ }^{27,28}$ Moreover, transfer to different cognitive domains was not assessed in some studies ${ }^{28-30}$ and most interventions lasted for 4 months at most. ${ }^{23,24,26-30}$ This duration might be too short since physical training interventions of 6 months or longer have shown most consistent effects on cognition. ${ }^{3,8}$ Therefore, we suggest that the promising findings in previous research are worth further investigation.

This study aims to compare two variations of simultaneous cognitive-physical training with an exclusively physical multicomponent program and to evaluate the effects of these programs on cognition in healthy elderly people. We hypothesize, first, that simultaneous cognitive-physical training may create additional beneficial effects on cognition, and second, that the two cognitive-physical training variations may lead to differential cognitive adaptations. Based on previous findings, reported earlier, we expect cognition to improve in all three programs. Furthermore, we aim to investigate the performance maintenance 1 year after the training interventions.

\section{Materials and methods Study design and participants}

This study was a randomized, controlled trial (RCT), including a three groups parallel 6-months training intervention and a 1-year nonintervention follow-up. Assessments of cognitive performance were performed four times: pretraining, after 3 months, 6 months (posttraining), and at 1-year follow-up. Data collection and training were performed at Geriatrische Klinik St Gallen, Switzerland. The study protocol was approved through the local ethics committee of the canton St Gallen, Switzerland (study number: EKSG 12/092) and registered at Current Controlled Trials ISRCTN70130279. No changes were made to the planned methods after trial commencement. Our reporting in the manuscript adheres to the CONSORT 2010 guidelines. ${ }^{31}$

Participants were recruited through a newspaper article, a local seniors organization, ${ }^{32}$ senior residence facilities, primary-care physicians, and via the websites of the city's geriatric hospital ${ }^{33}$ and the department of sports of the canton St Gallen. ${ }^{34}$ Interested persons were invited to an information event. We included male and female participants because both sexes are similarly affected by age-related cognitive decline. ${ }^{1}$ For eligibility, participants had to be older than 70 years, live independently, or at senior residence facilities, 
and had to sign the informed consent. Residents of retirement homes classified as 0,1 , or 2 within the Swiss classification system for health care requirements (BESA-levels, German abbreviation for Bewohner-Einstufungs- und AbrechnungsSystem) could enroll in the study. Level 0 means the person does not need care or treatment; levels 1-2 means, the person only needs little care or treatment. Seniors with diagnosed Alzheimer's disease, dementia, recent head injury, or a score $<22$ points $^{35}$ on the Mini Mental Status Examination (MMSE), ${ }^{36}$ which indicates cognitive impairment were excluded. Judgment by their primary care physician was required in the case of acute or instable chronic diseases (eg, stroke, diabetes), rapidly progressing or terminal illnesses before accepting a person for participation.

A priori power analysis (G*Power 3.1.3 Software $^{37}$ ) revealed a sample size of 75 participants in order to achieve $80 \%$ power for a three group pretest, 3 - and 6-months test design (25 participants per group). The $\alpha$-level was set at 0.05 and the effect size $f$ at 0.3 . The randomization scheme was generated with the website Randomization.com, ${ }^{38}$ applying block randomization to achieve three groups with a ratio of 1:1:1. Participants were blinded to the expected study outcome, while blinding of the investigators was not possible since they supervised and conducted training and testing sessions.

\section{Training programs}

Two 1-hour training sessions per week were performed in groups of five to six participants, under the instruction of two trained postgraduate students. At least 1 day was included between sessions for recovery. Training programs were based on current recommendations for physical fitness and fall prevention for the elderly. ${ }^{39-41}$ The three multicomponent programs consisted of 20 minutes aerobic endurance training (either video game dancing, treadmill memory training, or treadmill walking) and complementary strength and balance exercises (20 minutes each). The exercise training principles of progression and overload were applied for every training component, ${ }^{42}$ and they were adapted to each participant's abilities such that a moderate to vigorous intensity was achieved. ${ }^{39}$ In total, 52 sessions were performed within 6 months ( 26 weeks), with some participants missing certain sessions due to personal reasons. Sessions 25-32 (4 weeks) were performed individually according to a home exercise plan, due to Christmas holiday and 3-months test sessions. The home exercise plan comprised the same strength and balance exercises as instructed during normal training sessions, but no video game dancing and treadmill memory training. Compliance to the home exercise plan was assessed with a training diary.

\section{Video game dancing (DANCE)}

Program DANCE included virtual reality video game dancing as a simultaneous cognitive-physical training (Figure 1A). This training component combines an attention demanding cognitive task with a simultaneous motor coordination aspect. We used two Impact Dance Platforms (Positive Gaming BV, Haarlem, the Netherlands) and created various levels of difficulty in step patterns and frequency with the StepMania Software. ${ }^{43}$ Several styles of music were selected to add variety and meet preferences of participants. Participants stood on the one-by-one meter platform, which contained four pressure sensitive areas to detect steps forward, backward, to the left, and to the right, respectively. Stepping sequences were cued with arrows appearing on a large screen and had
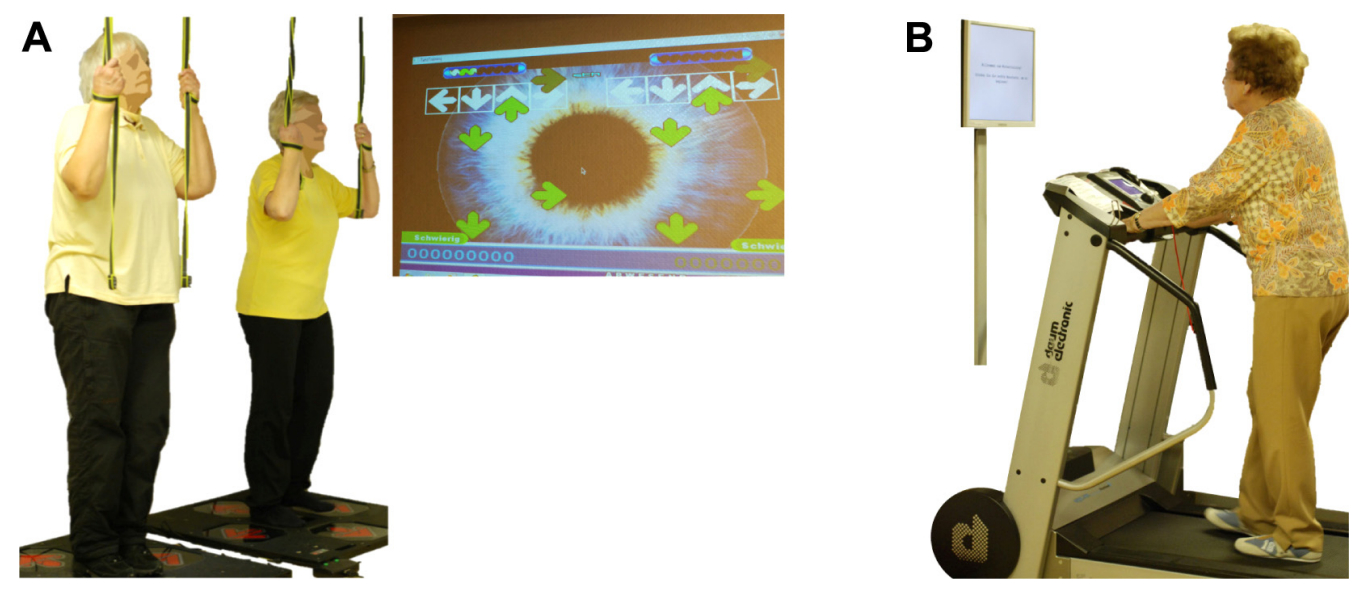

Figure I Simultaneous cognitive-physical training components: video game dancing (A) and treadmill memory training (B). In (A) two participants perform steps on a pressure sensitive platform to the rhythm of the music. Step timing and direction is cued with arrows on a screen. In (B) a participant is walking on a treadmill while performing verbal memory exercises presented on a computer screen. 
to be performed exactly when an arrow reached a highlighted area on the screen in order to achieve best scores in the game. Participants were holding on to ropes for security reasons. Training difficulty was adapted to each individual's coordination ability and was increased progressively.

\section{Treadmill memory training (MEMORY)}

Program MEMORY comprised treadmill walking with verbal memory exercise as a simultaneous cognitive-physical training (Figure 1B). Verbal memory training consisted of a computer-based serial position training that was presented on a computer screen in front of the treadmill, with a standard computer mouse as an input device. E-Prime 2.0 Professional software (Psychology Software Tools, Pittsburgh, PA, USA) was used to program the training. Participants were asked to memorize the correct sequence of 3-20 words lighting up one after the other for 3 seconds on the computer screen. Thereafter, a distraction task was followed where participants had to define if three presented words had a meaning or not. Then, the initially memorized words were presented again, either in the same or another sequence, and participants had to decide if the sequence remained the same or not, by pressing the mouse button. The initial level for this training was set at a sequence of three words and was extended by one word as soon as the participants reached $80 \%$ of correct answers within the level. Treadmill speed and inclination were set individually for each participant, such that a subjective rate of perceived exertion of five to seven points on the ten-point Borg scale was reached as recommended by the American College of Sports Medicine (ACSM) position stand on exercise with older adults. ${ }^{39}$

\section{Treadmill walking (PHYS)}

Program PHYS included aerobic treadmill walking without an additional cognitive task and acted as a reference group with exclusively physical training components. Participants were walking or running at a constant pace. Treadmill speed and inclination were set individually for each participant, such that a subjective rate of perceived exertion of five to seven points on the ten-point Borg scale was reached. ${ }^{39}$

\section{Complementary strength and balance exercises}

In addition to one of the three different aerobic training components described earlier, muscular strength and balance exercises complemented each program (Figure 2). Four to five strength exercises for lower and upper extremities and trunk stabilization were performed using own body weight, resistive rubber bands, and weight vests of maximally $10 \mathrm{~kg}$

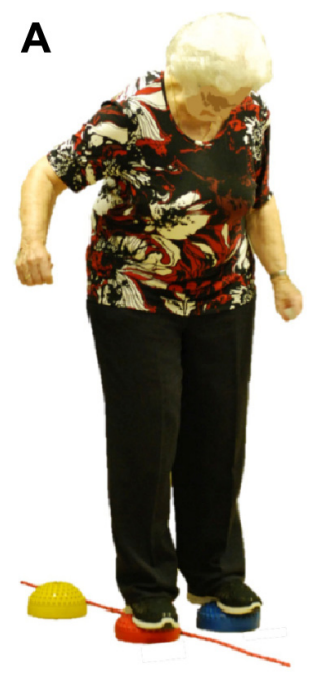

B

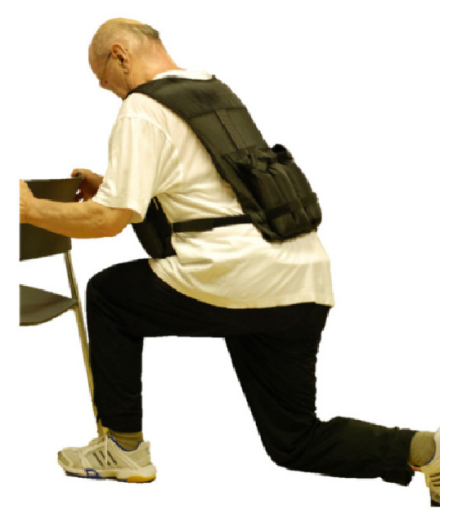

Figure 2 Examples of complementary balance $(\mathbf{A})$ and strength $(\mathbf{B})$ exercises. Notes: The participant in (A) tries to maintain balance while stepping from one object to the next (objects are soft rubber "stones" and a skipping rope) and (B) shows a participant performing split leg squats wearing a weight vest.

(1-3 sets, with $8-12$ repetitions, at slow to fast movement speed). Number of sets and repetitions were adapted individually for each participant, such that a subjective rate of perceived exertion of five to seven points on the ten-point Borg scale was reached. ${ }^{39}$ Balance training consisted of different exercises including two- and single-leg stance variations, either on the floor or on various types of instable surfaces (eg, foam and air pads, ropes, etc).${ }^{44}$ Exercise level, volume, and intensity were chosen according to the participants' individual abilities and increased progressively.

\section{Measurements}

\section{Cognitive tasks (primary outcome)}

Cognitive performance was measured by applying a test battery including nine "paper-and-pencil" tasks to assess transfer to different cognitive domains. Four of these tests were repeated at 1-year follow-up, while the other tests were excluded to reduce test time for participants. Executive function was measured with the Trail Making Test Part B (TMT-B), ${ }^{45}$ working memory was assessed with the Executive Control Task, ${ }^{46}$ and long-term visual memory was tested with three different parallel versions of the Paired-Associates Learning task; ${ }^{46}$ furthermore, long-term verbal memory was assessed with the German version ${ }^{47}$ of the Logical Memory subtest (Story Recall) from the Wechsler Memory Scale-Revised (WMS-R) ${ }^{48}$ whereby only one of two different stories from the original test was presented (story A) and no delayed recall after 30 minutes was performed; moreover, short-term verbal memory was measured with the Digit Forward and Backward 
Tasks from WMS-R, ${ }^{48}$ attention was tested with three different parallel versions of the Age Concentration Tests A and $\mathrm{B}^{49}$ (as an adaptation to the original test, we calculated "number of correct figures" divided by "time" as the test result); and finally, information processing speed was assessed with the Trail Making Test Part A (TMT-A) ${ }^{45}$ and the Digit Symbol Substitution Task (DSST) from Wechsler Adult Intelligence Scale-Revised (WAIS-R). ${ }^{50}$

\section{Training enjoyment (secondary outcome)}

Overall training enjoyment was assessed at 6-months test using the German eight-item version of the Physical Activity Enjoyment Scale (PACES). ${ }^{51,52}$ The average score of the eight items was used for statistical analysis. Additionally, we asked participants specifically about their enjoyment of the balance and the strength training, as well as the video game dancing, the treadmill memory training, or the treadmill walking. Thereby, we used the same scoring system from one to seven points (least to most enjoyment) as in the PACES. We assumed that training with cognitive elements would be enjoyed more than treadmill walking and that video game dancing would be enjoyed more than treadmill memory training. ${ }^{53}$

\section{Statistical analyses}

Group differences in the baseline demographic and performance data were compared with one-way analysis of variance (ANOVA). Multiple regression analysis with planned comparisons, including orthogonal contrast and polynomial trend coding, were applied to investigate training effects on the cognitive test battery for the 6-months training period. We produced contrast coding variables based on the hypotheses. The first contrast was set to compare the two combined cognitive-physical training groups with PHYS. The second contrast compared the two cognitive-physical training groups (DANCE versus MEMORY). According to the study design, comprising three time points of measurement, we created polynomial trend coding variables to assess the linear and quadratic trend. Effect code variables were produced for each group's individuals to account for subject effects. Repeated measures ANOVA with Bonferroni correction was applied for post hoc comparisons from pretest to 3-months test and from 3- to 6-months tests ( $P=0.025$ for two comparisons). Repeated measures of ANOVA were also used to assess differences between 6-months test and 1-year follow-up. Missing values from participants who completed the full 6-months trial but missed single test items due to health constraints or social obligations were replaced by the group mean value at the respective time point of measurement. One-way ANOVA with planned contrasts was performed to compare group differences in the training enjoyment questionnaire. Statistical calculations were performed with IBM SPSS Statistics software for Macintosh, version 22.0 (IBM Corp., Armonk, NY, USA) with a significance level of $\alpha=0.05$. Effect sizes, represented as $R^{2}$-change in the multiple regression analysis, were considered as small for $R^{2}$-change $=0.01$, medium for $R^{2}$-change $=0.06$ and large for $R^{2}$-change $=0.14$ and above; effect size $r$ from one-way ANOVA, was defined as small at $r=0.10$, medium at $r=0.30$, and large at $r=0.50$ and above. ${ }^{54}$

\section{Results}

Out of 89 participants initially enrolled, 71 participants completed the 6-months training intervention (20.2\% attrition) and were included in the analysis of the outcomes derived at pretest, 3- and 6-months tests. Time points and reasons for dropouts are presented in Figure 3. Dropouts were equally distributed between groups, and therefore, the final analyses were performed only in individuals who completed the 6-months intervention. Forty-seven participants were available for the 1-year follow-up test session and were included in the analysis of these outcomes. The following missing values from persons who completed the 6-months training were replaced by the group mean value: at pretest, three persons from DANCE and two persons from MEMORY missed TMT A and B, one person from DANCE missed four other items, and one person from PHYS missed seven test items; at 3-months test, one person from MEMORY missed all nine tests (this person did not miss any pretests). No missing values were evident at 6 months and follow-up tests. One cognitive task, the Digit Backward Task, was not analyzed because some participants applied a strategy that defeated the idea of the test. Participants' recruitment lasted from August 2012 until the end of September 2012, when pretests were performed. The training intervention lasted from October 2012 until the end of March 2013, with 3-months test at the beginning of January 2013 and 6-months test at the beginning of April 2013. One year later, in April 2014, follow-up test was performed. Table 1 shows baseline demographic characteristics and training compliance of the three intervention groups. Baseline cognitive performance data did not show significant differences between intervention groups for any of the nine cognitive transfer tests (TMT-A $P=0.351$; TMT-B $P=0.334$; Executive Control $P=0.652$; Paired Associates $P=0.156$; Story Recall $P=0.655$; Digit Forward $P=0.458$; Age Concentration A 


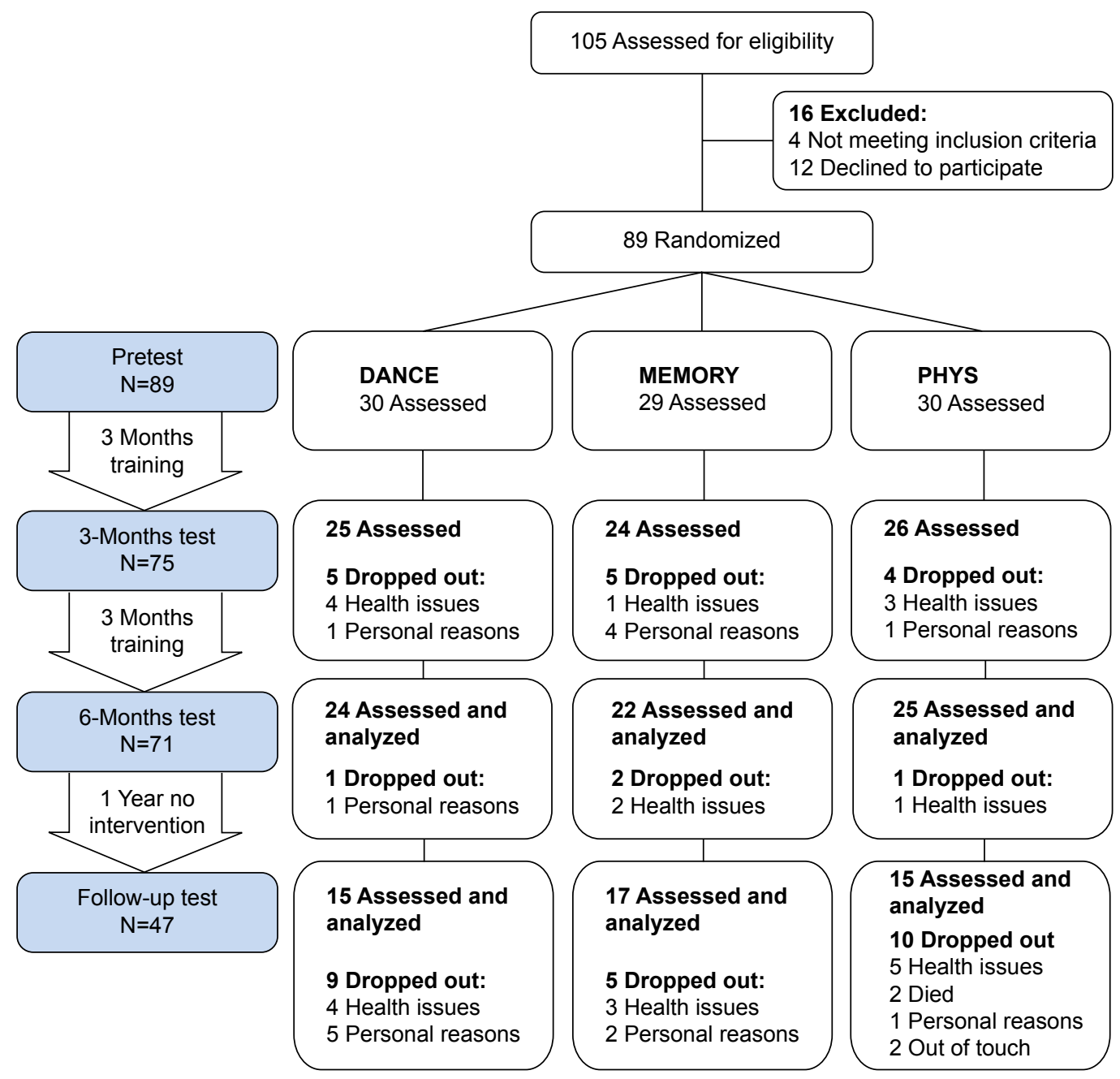

Figure 3 Trial design and participants' flow.

Notes: Participants were randomly assigned to one of two simultaneous cognitive-physical training groups (DANCE and MEMORY) or an exclusively physical multicomponent training group (PHYS) and were trained over 6 months twice weekly for I hour. Nine cognitive tests were assessed at pretest, 3-months test, and 6-months test. Four tests were repeated at I-year follow-up.

Abbreviations: DANCE, virtual reality video game dancing; MEMORY, treadmill walking with simultaneous verbal memory training; PHYS, treadmill walking.

$P=0.390$; Age Concentration B $P=0.346$; DSST $P=0.548$; all $P$-values two-tailed).

\section{Cognitive tasks}

Figures 4 and 5 depict performance development for the nine cognitive tasks. Statistical details of the multiple regression analysis over the first three time points of measurement, including two planned comparisons or contrasts, are provided in Table 2. In eight of nine cognitive tasks, except Digit Forward Task, linear global time effect showed significant performance improvement from pretest to 6-months test in each of the three intervention groups. The analysis of

Table I Baseline demographic characteristics and training compliance

\begin{tabular}{lllll}
\hline Variable & DANCE & MEMORY & PHYS & P-value, two tailed \\
\hline $\mathrm{N}$ & 24 & 22 & 25 & \\
Sex, female & $14,58.3 \%$ & $16,72.7 \%$ & $16,64.0 \%$ & 0.602 \\
Age, years & $77.3(6.3)$ & $78.5(5.1)$ & $80.8(4.7)$ & $\mathbf{0 . 0 7 9}^{\mathrm{t}}$ \\
MMSE, score & $28.4(1.4)$ & $28.3(1.2)$ & $28.0(1.7)$ & 0.533 \\
Education, years & $13.7(1.5)$ & $13.9(2.1)$ & $12.0(2.1)$ & $\mathbf{0 . 0 0 2 ^ { * * }}$ \\
Total training compliance (52 sessions) & $84.3 \%(12.7 \%)$ & $86.1 \%(9.1 \%)$ & $87.1 \%(7.9 \%)$ & 0.633 \\
Home-training compliance (eight sessions) & $79.9 \%(23.0 \%)$ & $90.0 \%(14.8 \%)$ & $83.5 \%(18.4 \%)$ & 0.201 \\
\hline
\end{tabular}

Notes: Data are means (standard deviation in brackets) or numbers. Bold values indicate significance or trend, $* * P<0.01$, ${ }^{\mathrm{t}} \mathrm{P}<0.10$ trend.

Abbreviations: MMSE, Mini Mental State Examination; DANCE, virtual reality video game dancing; MEMORY, treadmill walking with simultaneous verbal memory training; PHYS, treadmill walking. 
A

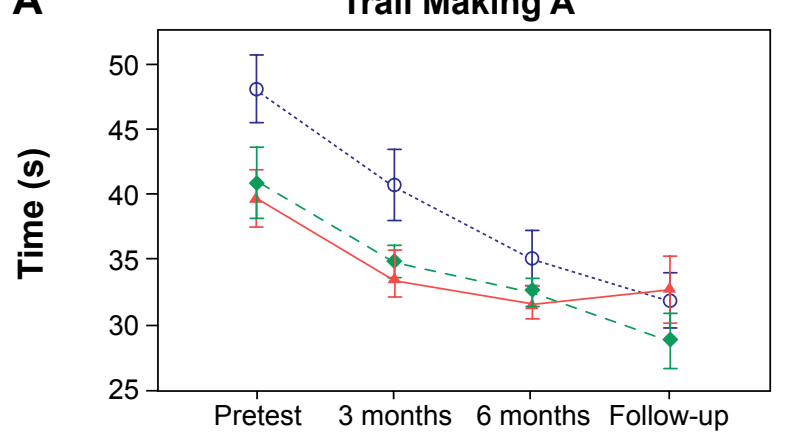

C

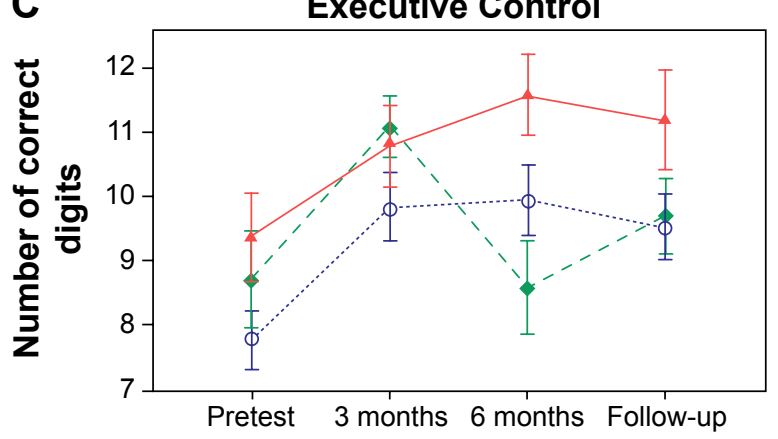

B

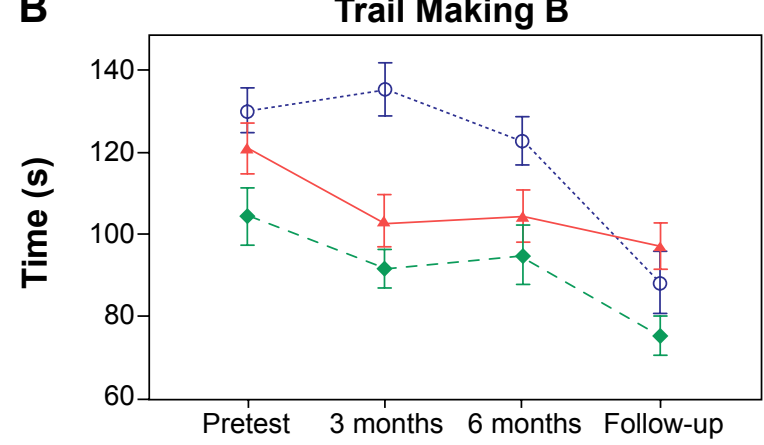

D

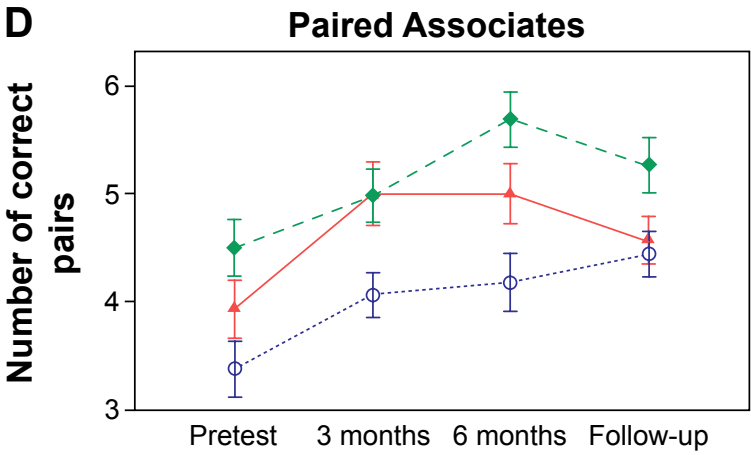

$\sim$ DANCE - - MEMORY -......PHYS

Figure 4 Cognitive performance developments in the four tests that included a I-year follow-up measurement.

Notes: Significant overall improvements were shown in all tests over the 6-months training period (graphs $\mathbf{A}-\mathbf{D}$ all $\mathbf{P}<0.05$, one tailed). In Trail Making B (graph B), only the two groups with a cognitive training component (DANCE and MEMORY) improved from pretest to 3-months test (trend $P=0.075$, one tailed). In Executive Control (graph C), different time courses of adaptation between DANCE and MEMORY were found (trend $P=0.05$ I, one tailed). From 6-months test to I-year follow-up test Trail Making B improved significantly (graph $\mathbf{B}, P=0.015$ ), while performance was maintained in the three other tests (graphs $\mathbf{A}, \mathbf{C}$, and $\mathbf{D}$ ). Error bars indicate \pm standard error of the mean. Abbreviations: DANCE, virtual reality video game dancing; MEMORY, treadmill walking with simultaneous verbal memory training; PHYS, treadmill walking.

performance maintenance from 6 months to follow-up test is shown in Table 3. Performance remained unchanged until 1-year follow-up test in three cognitive tasks and increased significantly in TMT-B.

The first contrast in the multiple regression analysis tested if the two simultaneous cognitive-physical interventions performed better compared to PHYS. Thereby no significant timexintervention interaction was found. Additional post hoc comparison for performance development in the TMT-B from pretest to 3-months test showed a small to moderate effect with a trend to significance for the timexintervention interaction between DANCE/MEMORY versus PHYS: the two groups with a cognitive training component reduced their time to complete the task, while PHYS was performing slower $(F[2,68]=1.95$, trend $P=0.075$ [one tailed for directional hypothesis], $r=0.17$ ). No other trend or significant timexintervention interaction was found for post hoc comparisons of the two separate 3-months training periods (data are not presented).

The second contrast tested differences between the two cognitive-physical interventions. There was a trend to a significant linear timexintervention interaction between DANCE and MEMORY in the Executive Control Task from pretest to 6-months test, reflecting different time courses of adaptation: DANCE improved continuously, while MEMORY showed an improvement over the first 3 months and a decrease of performance, back to baseline level, after the second 3 months of training $(F[1,136]=2.71$, trend $P=0.051$ [one tailed for directional hypothesis], $R^{2}$-change $=0.006$ ). Additional post hoc comparison of the development in the Executive Control Task from 3-months to 6-months tests revealed a significant timexintervention interaction with a small to moderate effect, also reflecting the aforementioned improvement for DANCE and the decline in MEMORY $(F[2,68]=3.20, P=0.024$ [one tailed for directional hypothesis], $r=0.21$ ).

\section{Training enjoyment}

Training enjoyment was measured at 6-months test in the 71 participants who completed the 6-months training. Results are presented in Figure 6. One-way ANOVA and planned contrasts did not show significant group differences for overall 

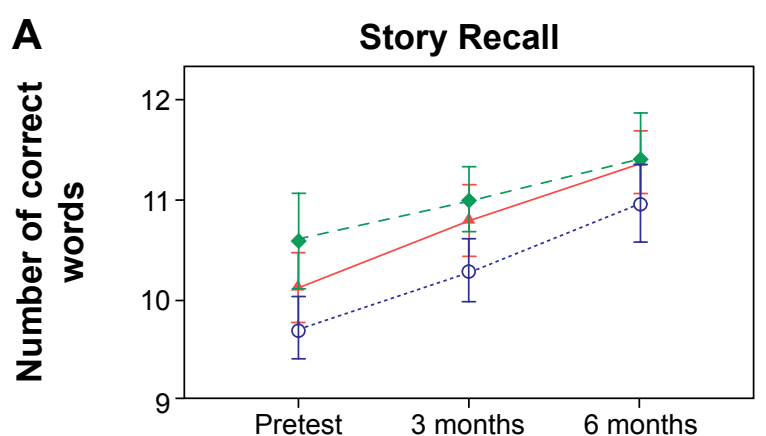

C

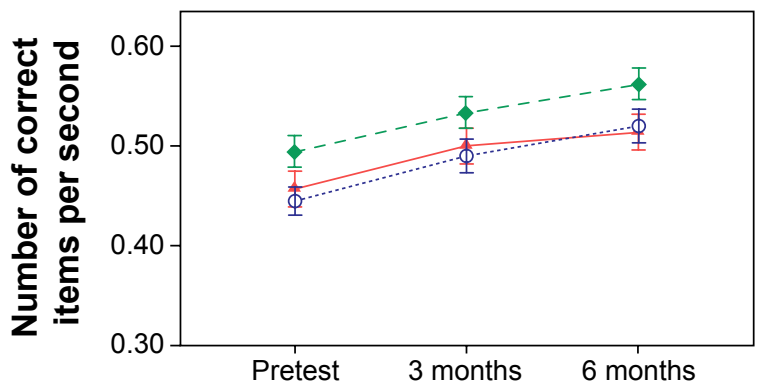

B

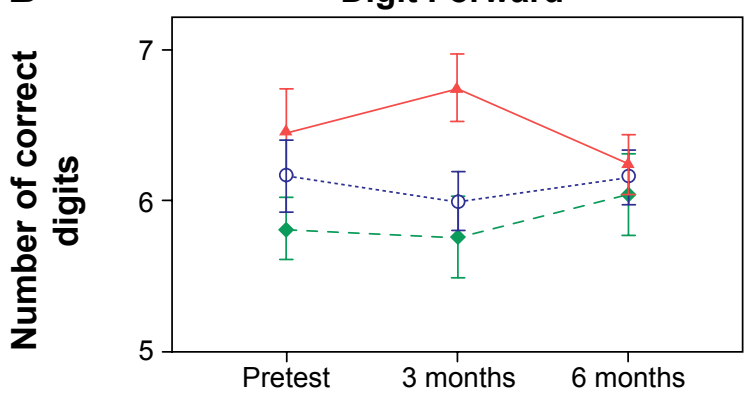

D Age Concentration B

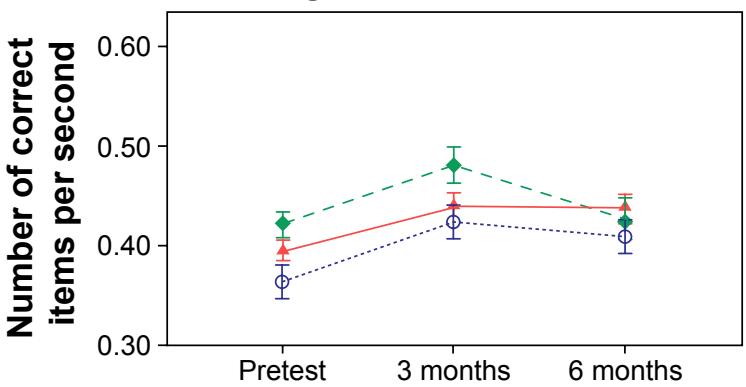

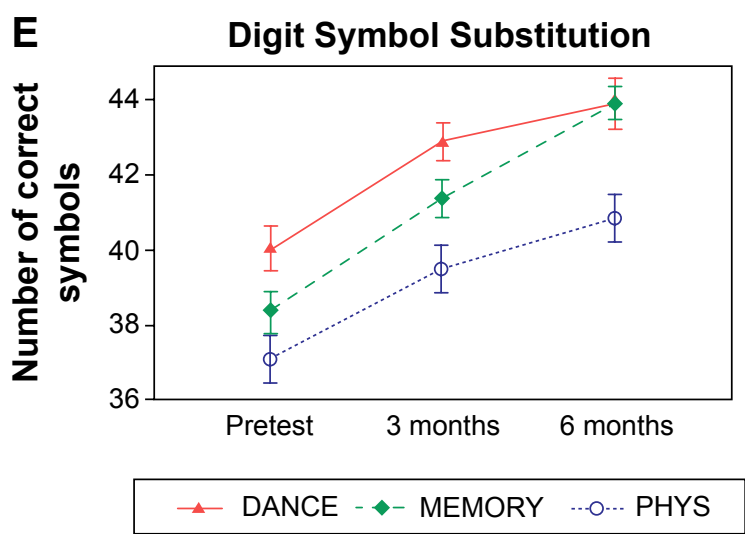

Figure 5 Cognitive performance developments in the five tests that did not include a I-year follow-up measurement.

Notes: Significant overall improvements were shown in the tests in graphs (A, C, $\mathbf{D}$, and $\mathbf{E})$ (all $\mathbf{P}<0.05$, one tailed) over the 6-months training period. No improvement was found in Digit Forward (graph B). Error bars indicate \pm standard error of the mean.

Abbreviations: DANCE, virtual reality video game dancing; MEMORY, treadmill walking with simultaneous verbal memory training; PHYS, treadmill walking.

training enjoyment (PACES, $P=0.606)$, training enjoyment of balance $(P=0.979)$, and strength training $(P=0.972)$. A trend to a significant contrast was found between the enjoyment of the two cognitive-physical training components (video game dancing and treadmill memory training) and the treadmill walking $(t[68]=1.503$, trend $P=0.069$ [one tailed for directional hypothesis], $r=0.18$ ). Participants seemed to favor the two cognitive-physical components over the treadmill walking.

\section{Discussion}

This study aimed to compare two simultaneous cognitivephysical training interventions with an exclusively physical multicomponent training program and to evaluate effects on cognition. The study comprised a 6-months training intervention and a 1-year follow-up. The two main findings were first, that the cognitive-physical programs were partially advantageous to boost performance in two measures of executive function (switching attention and working memory), thereby video game dancing resulted in transfer to an untrained cognitive domain (working memory); and second, that cognitive performance, including executive functions, long-term visual memory (episodic memory), and processing speed, was maintained until 1-year follow-up. These findings are important since executive functions, episodic memory, and processing speed are particularly affected by aging-related decline. ${ }^{55}$ Therefore, we suggest that simultaneous cognitive-physical 
Table 2 Multiple regression for the linear global time effect (from pretest to 3- and 6-months tests, $\mathrm{N}=7 \mathrm{I}$ ) and the interaction between orthogonal contrasts and time effect for the cognitive test battery

\begin{tabular}{|c|c|c|c|c|c|c|c|c|}
\hline $\begin{array}{l}\text { Dependent variable } \\
\text { (cognitive domain) }\end{array}$ & Predictor & $b$ & $95 \% \mathrm{Cl}$ & & SE $b$ & $\beta$ & $P$ one tailed & $R^{2}$-change \\
\hline Trail Making Part A & $A B C$ & -4.93 & -6.81 & -3.05 & 0.95 & -0.22 & $<0.00 I^{* * *}$ & 0.049 \\
\hline \multirow[t]{2}{*}{ (information processing speed) } & $A B \times C$ & 0.78 & -0.53 & 2.09 & 0.66 & 0.05 & 0.120 & 0.003 \\
\hline & $A \times B$ & 0.06 & -2.27 & 2.40 & 1.18 & 0.00 & 0.479 & 0.000 \\
\hline Trail Making Part B & $A B C$ & -5.57 & -11.46 & 0.32 & 2.98 & -0.08 & $0.032^{*}$ & 0.006 \\
\hline \multirow[t]{2}{*}{ (executive function, shifting) } & $A B \times C$ & -0.93 & -5.03 & 3.18 & 2.08 & -0.02 & 0.328 & 0.000 \\
\hline & $A \times B$ & -1.76 & -9.07 & 5.56 & 3.70 & -0.02 & 0.318 & 0.000 \\
\hline Executive Control & $A B C$ & 0.70 & 0.14 & 1.27 & 0.29 & 0.11 & $0.008 * *$ & 0.013 \\
\hline \multirow[t]{2}{*}{ (executive function, working memory) } & $A B \times C$ & -0.19 & -0.58 & 0.20 & 0.20 & -0.04 & 0.170 & 0.002 \\
\hline & $A \times B$ & 0.58 & -0.12 & 1.28 & 0.35 & 0.08 & $0.05 I^{t}$ & 0.006 \\
\hline Paired-Associates Learning & $A B C$ & 0.51 & 0.26 & 0.76 & 0.13 & 0.21 & $<0.00 I^{* * *}$ & 0.043 \\
\hline \multirow[t]{2}{*}{ (long-term visual memory) } & $A B \times C$ & 0.05 & -0.12 & 0.23 & 0.09 & 0.03 & 0.272 & 0.001 \\
\hline & $A \times B$ & -0.03 & -0.34 & 0.28 & 0.16 & -0.01 & 0.426 & 0.000 \\
\hline Story Recall & $A B C$ & 0.55 & 0.19 & 0.92 & 0.18 & 0.13 & $0.002 * *$ & 0.017 \\
\hline \multirow[t]{2}{*}{ (long-term verbal memory) } & $A B \times C$ & -0.04 & -0.29 & 0.22 & 0.13 & -0.01 & 0.389 & 0.000 \\
\hline & $A \times B$ & 0.11 & -0.35 & 0.56 & 0.23 & 0.02 & 0.319 & 0.000 \\
\hline Digit Forward & $A B C$ & 0.00 & -0.23 & 0.23 & 0.12 & 0.00 & 0.493 & 0.000 \\
\hline \multirow[t]{2}{*}{ (short-term verbal memory) } & $A B \times C$ & 0.00 & -0.16 & 0.16 & 0.08 & 0.00 & 0.487 & 0.000 \\
\hline & $A \times B$ & -0.11 & -0.39 & 0.18 & 0.14 & -0.04 & 0.225 & 0.002 \\
\hline \multirow{3}{*}{$\begin{array}{l}\text { Age Concentration Test A (concentration, } \\
\text { attention) }\end{array}$} & $A B C$ & 0.03 & 0.02 & 0.05 & 0.01 & 0.20 & $<0.00 I^{* * *}$ & 0.040 \\
\hline & $A B \times C$ & 0.00 & -0.01 & 0.01 & 0.01 & -0.02 & 0.366 & 0.000 \\
\hline & $A \times B$ & 0.00 & -0.02 & 0.02 & 0.01 & -0.01 & 0.407 & 0.000 \\
\hline \multirow{3}{*}{$\begin{array}{l}\text { Age Concentration Test B (concentration, } \\
\text { attention) }\end{array}$} & $A B C$ & 0.01 & 0.00 & 0.03 & 0.01 & 0.08 & $0.036 *$ & 0.007 \\
\hline & $A B \times C$ & 0.00 & -0.01 & 0.01 & 0.01 & -0.01 & 0.433 & 0.000 \\
\hline & $A \times B$ & 0.01 & -0.01 & 0.03 & 0.01 & 0.05 & 0.140 & 0.002 \\
\hline \multirow{3}{*}{$\begin{array}{l}\text { Digit Symbol Substitution } \\
\text { (information processing speed) }\end{array}$} & $A B C$ & 2.20 & 1.62 & 2.77 & 0.29 & 0.18 & $<0.00 I^{* * *}$ & 0.033 \\
\hline & $A B \times C$ & 0.16 & -0.24 & 0.56 & 0.20 & 0.02 & 0.216 & 0.000 \\
\hline & $A \times B$ & -0.44 & -1.15 & 0.27 & 0.36 & -0.03 & 0.113 & -0.001 \\
\hline
\end{tabular}

Notes: $A B C$, linear global time effect; $A B \times C$, linear timexintervention interaction DANCE/MEMORY versus $P H Y S$; $A \times B$, linear time $\times$ intervention interaction $D A N C E$ versus MEMORY. A, DANCE; B, MEMORY; C, PHYS. Bold values indicate significance or trend, $* P<0.05, * * P<0.01, * * * P<0.001$, ${ }^{t} P<0.10$ trend.

Abbreviations: DANCE, virtual reality video game dancing; MEMORY, treadmill walking with simultaneous verbal memory training; $\mathrm{PHYS}$, treadmill walking; $\mathrm{Cl}$, confidence interval; SE, standard error of the mean.

training should be integrated in training programs aiming to improve cognition in the elderly.

\section{Does simultaneous cognitive-physical training boost cognitive performance?}

We found one indication in our results that supported the hypothesis that the simultaneous cognitive-physical programs (DANCE, MEMORY) had advantages over an exclusively physical intervention (PHYS) in terms of cognitive adaptations. Both cognitive-physical interventions showed larger improvements in the TMT-B compared to PHYS within the initial 3-months training period (Figure 4B). This result showed a trend to statistical significance but seems worth mentioning due to the small to moderate effect size.

Table 3 Repeated measures ANOVA from 6-months test to follow-up test, N=47

\begin{tabular}{llll}
\hline $\begin{array}{l}\text { Dependent variable } \\
\text { (cognitive domain) }\end{array}$ & Effect & $\mathbf{F ( 2 , 4 4 )}$ & P two tailed \\
\hline Trail Making Part A & Time & 0.104 & 0.748 \\
(information processing speed) & Timexintervention & 0.664 & 0.520 \\
Trail Making Part B & Time & 6.444 & $\mathbf{0 . 0 1 5}$ \\
(executive function, shifting) & Timexintervention & 0.372 & 0.691 \\
Executive Control & Time & 0.110 & 0.741 \\
(executive function, working memory) & Timexintervention & 1.086 & 0.346 \\
Paired-Associates Learning & Time & 1.133 & 0.36 \\
(long-term visual memory) & Timexintervention & 0.216 & 0.293 \\
\hline
\end{tabular}

Notes: $* P<0.05$. Bold values indicate significance or trend.

Abbreviation: ANOVA, analysis of variance. 


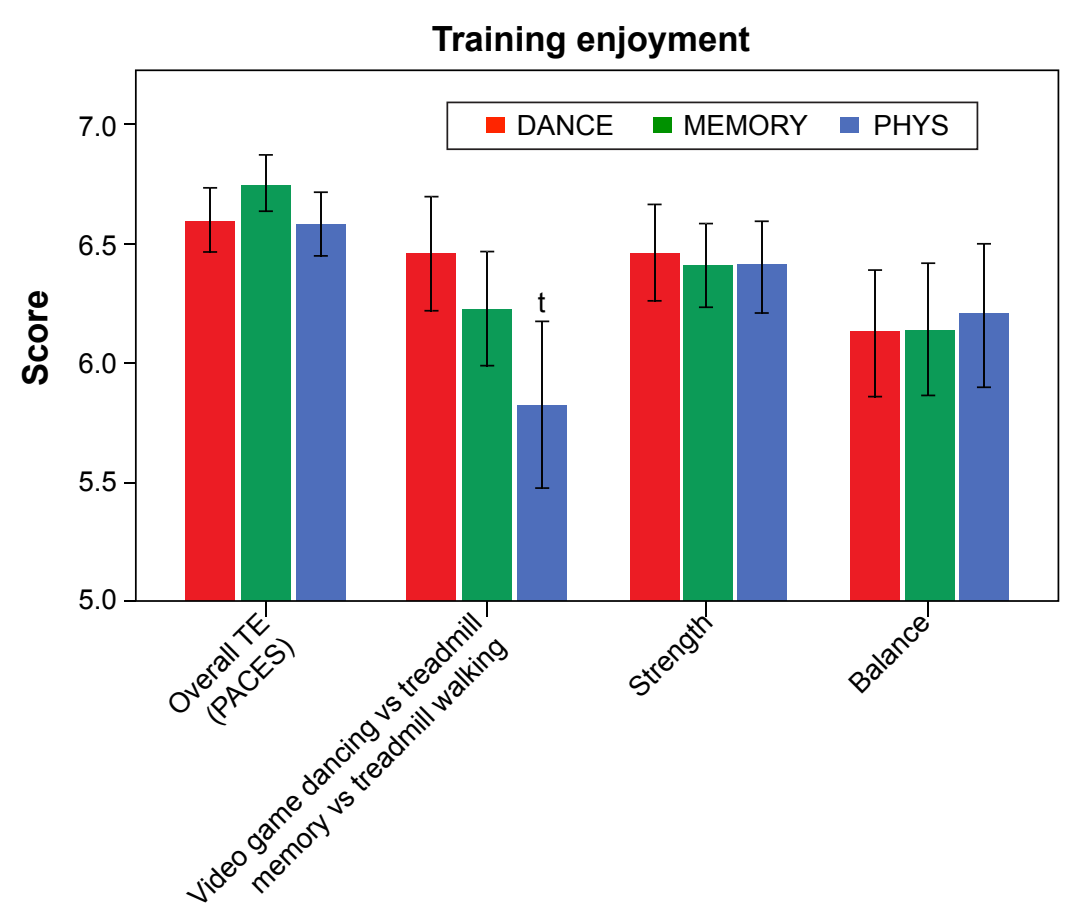

Figure 6 Comparison of training enjoyment in the three interventions.

Notes: No group differences were shown for overall training enjoyment (PACES), strength, and balance training (all $P>0.05$ ). The two cognitive-physical training components (video game dancing and treadmill memory) tended to be enjoyed more than treadmill walking (trend $P=0.069$, one tailed). Scores system is from one to seven points (least to maximal enjoyment), ${ }^{t}<0.10$ trend, error bars indicate \pm standard error of the mean.

Abbreviations: PACES, Physical Activity Enjoyment Scale; TE, training enjoyment; DANCE, virtual reality video game dancing; MEMORY, treadmill walking with simultaneous verbal memory training; PHYS, treadmill walking.

The TMT-B reflects the ability of shifting attention, which is a dimension of executive function. This ability might have been trained through the simultaneous performance of cognitive and physical activities in DANCE and MEMORY in the way that attention had to be shifted continuously between the two activities. The dual-task situation in the treadmill memory training possibly had some impact on cognitive shifting ability because treadmill walking itself required a certain amount of attention from the elderly participants to be executed safely. A similar result related to cognitive shifting was demonstrated in an investigation that compared effects on cognition after contemporary dancing, Tai Chi, or balance training. ${ }^{56}$ Thereby, only contemporary dancing, which can be regarded as a modality of simultaneous cognitive-physical activity, had an effect on cognition and particularly on switching attention as assessed with the Rule Shift Cards Sorting Test. ${ }^{57}$ Interestingly, a recent extensive investigation with 182 participants by van het Reve and de Bruin did not show this additional effect on shifting attention after 3 months of sequential cognitive and physical training compared to exclusively physical training (strength and balance exercises). ${ }^{58}$ This observation supports the benefits from simultaneously performed cognitive-physical training over sequential cognitive and physical training programs. In our study, participants of PHYS had about 2 years less school education compared to the other groups despite randomization. However, we would argue that this difference had no influence on the development of cognitive outcomes, since baseline cognitive measures and MMSE scores were not statistically different. Furthermore, adaptation patterns were similar in PHYS compared to the other groups in several cognitive outcomes. We conclude that additional cognitive functions, particularly switching attention, are promoted by the dual-task situation in simultaneous cognitive-physical programs and further research is warranted to substantiate or refute this assumption.

The expected differential adaptation patterns from DANCE versus MEMORY were confirmed in the results of the Executive Control Task (Figure 4C), which reflects working memory as another dimension of the executive functions: different time courses of adaptation from pretest, to 3-months, and 6-months tests for DANCE versus MEMORY were found, with superior performance in DANCE after 6-months training. This result was supported by a significant timexintervention interaction with small to moderate effect size in the specific analysis of the second 3-months training period. Within this period DANCE improved, whereas MEMORY deteriorated and PHYS remained unchanged. 
Our finding confirms the previously noted importance of applying longer training durations (6 months or longer) to assess cognitive adaptation patterns and to achieve larger training gains from physical interventions. ${ }^{3,8,59}$ More importantly, the result represents an adaptation from video game dancing in an untrained cognitive domain (working memory) or a so-called transfer effect. Previous studies on combined cognitive-physical training failed to produce cognitive transfer effects but reported training specific adaptations: for instance, Theill et $\mathrm{al}^{27}$ demonstrated performance gains in the Executive Control Task after simultaneous cognitivephysical and single cognitive training, which both contained specific working memory exercises. Similarly, van het Reve and de Bruin $^{58}$ reported a training specific adaptation after a 3-months computerized divided attention training, which was contained in a sequential cognitive-physical program. In summary, the present study provides first indications that simultaneous cognitive-physical training boosts particular executive functions (shifting attention and working memory) depending on the duration of the intervention, and that the video game dancing leads to cognitive transfer in working memory. However, further investigations are necessary to substantiate this finding. Improvements of executive functions in seniors are clinically important because they are critical for the regulation of gait, are related to fall risk, ${ }^{60}$ and are prone to aging-related decline in general. ${ }^{55}$

\section{Are cognitive training effects maintained after cessation of the training intervention?}

Training gains were preserved in our study in three out of four follow-up tests over 1 year without any further training intervention being applied. Surprisingly, performance kept increasing in the TMT-B from 6-months test to follow-up test in all groups, which may reflect a delayed response to the intervention. We did not systematically assess the amount of training that participants might have taken up individually after cessation of the intervention. Therefore, we cannot estimate a possible effect of additional individual training on cognitive measures at follow-up. Maintenance of cognitive performance was reported previously after different kinds of training interventions. For instance, a 1-year follow-up cognitive assessment after 6 months of either indoor cycling or stretching and coordination training demonstrated maintenance of selective attention ( $\mathrm{d} 2$ test) and episodic memory learning. ${ }^{61}$ However, only the subgroup with a high level of cardiovascular fitness, measured at follow-up, was able to preserve performance in episodic memory recognition, while the low-fit subgroup deteriorated from postintervention to 1-year follow-up. This finding indicates the importance of cardiovascular fitness as a mediator to maintain certain cognitive abilities. A 5-year follow-up study also reported sustained effects in a composite "cognitive function" score after sequential cognitive-physical training (effect size $\left.d_{+}=0.75\right),{ }^{62}$ but no performance maintenance was found after exclusively physical training comprising balance and coordination exercises. This finding stands in contradiction to our own result and may support the necessity of multicomponent physical programs containing aerobic endurance and muscular strength exercises for long-term performance maintenance of cognition. Finally, a meta-analysis including seven studies with exclusively cognitive interventions found persistent cognitive enhancements over different follow-up periods from 3 months up to 5 years. ${ }^{63}$ Considering the existing literature and our own results, it may be summarized that long-term cognitive performance maintenance can be evident after both, exclusively cognitive or multicomponent physical training containing aerobic endurance and strength exercises, as well as after sequential or simultaneous cognitive-physical interventions. However, which type of intervention might be superior in this respect needs further investigation.

\section{Can simultaneous cognitive-physical and exclusively physical multicomponent training programs elicit broad cognitive adaptations?}

A significant global linear time effect in the regression analyses of eight out of nine cognitive tests was found in this study for all three interventions taken together. Therefore, our results might extend the findings from the majority of interventions and meta-analyses with exclusively physical training demonstrating improvements in different cognitive dimensions. ${ }^{8-11,64-68}$ However, due to the lack of a passive control group, to account for learning effects from repeated measurements, we are not able to display training effects exclusively. Nonetheless, based on similar results from the literature, the long intervals of 3 months between test sessions and the application of parallel versions in some of the cognitive tests, we assume that performance improvements can at least partly be accounted for as training effects.

Several neurobiological and physiological mechanisms have been suggested to link physical training with benefits on cognitive performance: these are increased neurogenesis and synaptogenesis in the cortical structure, promotion of cerebral metabolism, alterations of neurotransmitter and neurotrophic factor levels, availability of cerebral oxygen 
and glucose, and reduced oxidative stress. ${ }^{69}$ In particular, the cardiovascular fitness hypothesis has been promoted to relate aerobic fitness and cognition. Thereby, aerobic training was found to affect certain mechanisms, such as cerebral blood flow, brain-derived neurotrophic factor, and cerebral structure, which are also associated with increased cognitive performance. ${ }^{69}$ Nevertheless, a meta-analysis by Etnier et $\mathrm{al}^{70}$ failed to support the relation between aerobic fitness and cognition. The authors argued that aerobic fitness itself might not be sensitive enough to indicate cognitive adaptations from aerobic exercise training, whereby the underlying adaptations of aerobic training might be more sensitive. ${ }^{70}$ For instance, the cerebral circulation hypothesis relies on studies that have found elevated oxygen and glucose transport to the brain, leading to improved cognitive performance. ${ }^{71}$ Furthermore, the neurotrophic stimulation hypothesis suggests that training-induced enhancement of brain-derived neurotrophic factor stimulates neurogenesis and thereby positively affects learning and mental performance ${ }^{69}$ Finally, the neuroadrenergic hypothesis proposed that cardiovascular training promoted neurotransmitter availability, such as noradrenaline, adrenaline, and serotonin, which are thought to be related to memory storage and retrieval. ${ }^{70,72}$ As indicated earlier, some recent studies also demonstrated that strength ${ }^{12}$ and coordination ${ }^{11}$ training induced changes in hemodynamic brain activity or elevated activation of certain brain networks, respectively, which were associated with improved cognition.

The importance of the physical part of a simultaneous cognitive-physical training intervention in older adults was supported by Theill et $\mathrm{al}^{27}$ who reported improvements in long-term visual memory (Paired-Associates Task) after simultaneous treadmill walking and memory training, but not after exclusively cognitive training. Additionally, two meta-analytic studies pointed out that exclusively cognitive training programs increased performance only on related or training-specific tasks and no cognitive transfer effects were evident. ${ }^{15,16}$ This was also confirmed by the recent review from Oei and Patterson ${ }^{17}$ who investigated transfer effects in video game training studies. However, some cognitive training studies reported broad improvements from cognitive training, particularly from extended but not from strategy training approaches. ${ }^{14}$ Extended practice refers to the training of basic cognitive abilities, such as choice response time or phoneme span, which are used in different cognitive activities. Additionally, a recent meta-analysis by Hindin and Zelinski ${ }^{13}$ found similar effect sizes in extended cognitive training compared to aerobic exercise training, although different neurophysiological mechanisms would likely have led to these effects. Nevertheless, it appears that physical and combined cognitive-physical training interventions may be more beneficial than exclusively cognitive training interventions for older adults to enhance a broad range of cognitive abilities. Such training programs should therefore be implemented in the clinical prevention of cognitive impairments, which are widely prevalent in older adults. ${ }^{1}$

\section{Strengths and limitations}

Methodological strengths of this study were the comparably large number of participants, the long training period with follow-up measurements, and the broad cognitive testing battery to assess several dimensions of cognition. Some limitations have to be considered as well. First, the specific effects of the two simultaneous training modalities could not be identified exactly because of the combination with the multiple physical components (strength and balance training). However, this was not the focus of this study, since we explicitly aimed at evaluating effects from different multicomponent programs. Second, the conclusions and recommendations from this study are limited to physically and mentally healthy seniors, because following the selection criteria such participants were recruited. Training effects might have been even larger in a population of lower physical and mental status. This assumption is based on the exercise training principle "Initial Values" stating that improvement in the outcome of interest will be greatest in those with lower initial values. ${ }^{42}$ Those with lowest levels of fitness theoretically have greatest room for improvement. It seems, therefore, important and warranted to repeat the study design in a more vulnerable population exhibiting impairments in fitness and/or cognitive domains. Further, as mentioned earlier, we did not include a passive control group in the design of the study, which means that we could not exactly differentiate between training effects and learning effects from repeated testing. However, this was not the main focus of the present study. Although participants were blinded to the expected study outcome, blinding of the investigators was not possible since they also supervised and conducted training and testing sessions. This is an additional limitation to this study.

\section{Conclusion}

We demonstrated that multicomponent simultaneous cognitive-physical training programs have the potential to boost particular executive functions (including shifting attention and working memory) in healthy older adults compared to an exclusively physical multicomponent program. 
Importantly, performance levels in executive functions, long-term visual memory (episodic memory), and processing speed were maintained over 1 year after all three programs. The novel training concepts of simultaneous cognitivephysical activity tended to be enjoyed more by seniors than traditional training and led to training specific as well as to transfer adaptations in cognition. Therefore, we recommend multicomponent simultaneous cognitive-physical training programs to enhance particular executive functions in older adults. Such programs may potentially counteract the large prevalence of cognitive impairments and decline in the elderly, inherently leading to more independence and a better quality of life. Future studies should also investigate the neurological background of cognitive behavioral performance enhancements to shed light on the interconnection between plasticity of cognition, brain function, and brain structure.

\section{Acknowledgments}

This work was supported by the Zürcher Kantonalbank within the framework of sponsoring of movement sciences, sports, and nutritional sciences at ETH Zurich. Zürcher Kantonalbank had no influence on the study design and the analyses presented in this paper, had no access to the data, and did not contribute to this manuscript in any way. The authors would like to thank PD Dr med. Thomas Münzer, chief physician, and the management of Geriatrische Klinik St Gallen, Switzerland, for supporting the study and providing room for training and data acquisition. Furthermore, we thank our postgraduate students, Stefan Holenstein, Fabienne Hüppin, Manuela Kobelt, Alexandra Schättin, and Sara Tomovic for training instruction and helping with data acquisition. We highly appreciate the support of the team of physiotherapists at Geriatrische Klinik St Gallen, and particularly the support from Carmen Fürer and Carole Scheidegger who initially put forward the idea of performing the study at their institution. Last but not the least, we would like to thank all the participants for their enthusiasm, kindness, and patience during our extensive training and testing interventions.

\section{Author contributions}

PE, study preparation and conception, participants' recruitment, data acquisition, statistical analysis, data interpretation, drafting manuscript; VS, study conception, conception of cognitive test battery, data interpretation, revising manuscript; MA, study preparation, training instruction, data acquisition, data interpretation, revising manuscript; NT, study conception, conception of serial position training, supporting statistical analysis, data interpretation, revising manuscript; EDB, study conception, data interpretation, revising manuscript. All authors read and approved the final manuscript.

\section{Disclosure}

The authors report no conflicts of interest in this work.

\section{References}

1. Scafato E, Gandin C, Galluzzo L, et al; I.PR.E.A. Working Group (Italian PRoject on Epidemiology of Alzheimer's disease). Prevalence of aging-associated cognitive decline in an Italian elderly population: results from cross-sectional phase of Italian PRoject on Epidemiology of Alzheimer's disease (IPREA). Aging Clin Exp Res. 2010; 22(5-6):440-449.

2. Williams KN, Kemper S. Interventions to reduce cognitive decline in aging. J Psychosoc Nurs Ment Health Serv. 2010;48(5):42-51.

3. Erickson KI, Weinstein AM, Lopez OL. Physical activity, brain plasticity, and Alzheimer's disease. Arch Med Res. 2012;43(8):615-621.

4. Lautenschlager NT, Cox K, Cyarto EV. The influence of exercise on brain aging and dementia. Biochim Biophys Acta. 2012;1822(3):474-481.

5. Gregory MA, Gill DP, Petrella RJ. Brain health and exercise in older adults. Curr Sports Med Rep. 2013;12(4):256-271.

6. Gomez-Pinilla F, Hillman C. The influence of exercise on cognitive abilities. Compr Physiol. 2013;3(1):403-428.

7. Hotting K, Roder B. Beneficial effects of physical exercise on neuroplasticity and cognition. Neurosci Biobehav Rev. 2013;37(9 pt B): 2243-2257.

8. Colcombe S, Kramer AF. Fitness effects on the cognitive function of older adults: a meta-analytic study. Psychol Sci. 2003;14(2):125-130.

9. Smith PJ, Blumenthal JA, Hoffman BM, et al. Aerobic exercise and neurocognitive performance: a meta-analytic review of randomized controlled trials. Psychosom Med. 2010;72(3):239-252.

10. Chang YK, Pan CY, Chen FT, Tsai CL, Huang CC. Effect of resistanceexercise training on cognitive function in healthy older adults: a review. J Aging Phys Act. 2012;20(4):497-517.

11. Voelcker-Rehage C, Godde B, Staudinger UM. Cardiovascular and coordination training differentially improve cognitive performance and neural processing in older adults. Front Hum Neurosci. 2011;5:26.

12. Liu-Ambrose T, Nagamatsu LS, Voss MW, Khan KM, Handy TC. Resistance training and functional plasticity of the aging brain: a 12-month randomized controlled trial. Neurobiol Aging. 2012;33(8): $1690-1698$.

13. Hindin SB, Zelinski EM. Extended practice and aerobic exercise interventions benefit untrained cognitive outcomes in older adults: a meta-analysis. J Am Geriatr Soc. 2012;60(1):136-141.

14. Zelinski EM. Far transfer in cognitive training of older adults. Restor Neurol Neurosci. 2009;27(5):455-471.

15. Papp KV, Walsh SJ, Snyder PJ. Immediate and delayed effects of cognitive interventions in healthy elderly: a review of current literature and future directions. Alzheimers Dement. 2009;5(1):50-60.

16. Noack H, Lovden M, Schmiedek F, Lindenberger U. Cognitive plasticity in adulthood and old age: gauging the generality of cognitive intervention effects. Restor Neurol Neurosci. 2009;27(5):435-453.

17. Oei AC, Patterson MD. Are videogame training gains specific or general? Front Syst Neurosci. 2014;8:54.

18. Lustig C, Shah P, Seidler R, Reuter-Lorenz PA. Aging, training, and the brain: a review and future directions. Neuropsychol Rev. 2009; 19(4):504-522.

19. Schaefer S, Schumacher V. The interplay between cognitive and motor functioning in healthy older adults: findings from dual-task studies and suggestions for intervention. Gerontology. 2011;57(3):239-246.

20. Kraft E. Cognitive function, physical activity, and aging: possible biological links and implications for multimodal interventions. Neuropsychol Dev Cogn B Aging Neuropsychol Cogn. 2012;19(1-2): 248-263. 
21. Law LL, Barnett F, Yau MK, Gray MA. Effects of combined cognitive and exercise interventions on cognition in older adults with and without cognitive impairment: a systematic review. Ageing Res Rev. 2014; 15:61-75.

22. Thom JM, Clare L. Rationale for combined exercise and cognitionfocused interventions to improve functional independence in people with dementia. Gerontology. 2011;57(3):265-275.

23. Legault C, Jennings JM, Katula JA, et al; SHARP-P Study Group. Designing clinical trials for assessing the effects of cognitive training and physical activity interventions on cognitive outcomes: the Seniors Health and Activity Research Program Pilot (SHARP-P) study, a randomized controlled trial. BMC Geriatr. 2011;11:27.

24. Fabre C, Chamari K, Mucci P, Masse-Biron J, Prefaut C. Improvement of cognitive function by mental and/or individualized aerobic training in healthy elderly subjects. Int J Sports Med. 2002;23(6):415-421.

25. Oswald WD, Rupprecht R, Gunzelmann T, Tritt K. The SIMA-project: effects of 1 year cognitive and psychomotor training on cognitive abilities of the elderly. Behav Brain Res. 1996;78(1):67-72.

26. O'Dwyer S. The effect of exercise training, and combined exercise and cognitive training, on cognitive and physical function in older adults: A randomized controlled trial and qualitative evaluation [dissertation]. Australia: University of Queensland; 2009.

27. Theill N, Schumacher V, Adelsberger R, Martin M, Jancke L. Effects of simultaneously performed cognitive and physical training in older adults. BMC Neurosci. 2013;14:103.

28. Pichierri G, Coppe A, Lorenzetti S, Murer K, de Bruin ED. The effect of a cognitive-motor intervention on voluntary step execution under single and dual task conditions in older adults: a randomized controlled pilot study. Clin Interv Aging. 2012;7:175-184.

29. Pichierri G, Murer K, de Bruin ED. A cognitive-motor intervention using a dance video game to enhance foot placement accuracy and gait under dual task conditions in older adults: a randomized controlled trial. BMC Geriatr. 2012;12:74.

30. Forte R, Boreham CA, Leite JC, et al. Enhancing cognitive functioning in the elderly: multicomponent vs resistance training. Clin Interv Aging. 2013;8:19-27.

31. Moher D, Hopewell S, Schulz KF, et al. CONSORT 2010 explanation and elaboration: updated guidelines for reporting parallel group randomised trials. $B M J .2010 ; 340: \mathrm{c} 869$.

32. Pro Senectute St Gallen [homepage on the Internet]. Available from: http://www.sg.pro-senectute.ch. Accessed August 8, 2012.

33. Geriatrische Klinik St Gallen [homepage on the Internet]. Available from: http://www.gesundheitundalter.ch/Home/GeriatrischeKlinik/ Portrait/tabid/106/Default.aspx. Accessed August 8, 2012.

34. Amt für Sport Kanton St Gallen [homepage on the Internet]. Available from: http://www.sg.ch/home/bildung/sport/Erwachsene.html. Accessed August 8, 2012.

35. MacKenzie DM, Copp P, Shaw RJ, Goodwin GM. Brief cognitive screening of the elderly: a comparison of the Mini-Mental State Examination (MMSE), Abbreviated Mental Test (AMT) and Mental Status Questionnaire (MSQ). Psychol Med. 1996;26(2):427-430.

36. Folstein MF, Folstein SE, McHugh PR. "Mini-mental state". A practical method for grading the cognitive state of patients for the clinician. J Psychiatr Res. 1975;12(3):189-198.

37. Faul F, Erdfelder E, Lang AG, Buchner A. G*Power 3: a flexible statistical power analysis program for the social, behavioral, and biomedical sciences. Behav Res Methods. 2007;39(2):175-191.

38. Randomization.com [homepage on the Internet]. Available from: http:// randomization.com. Accessed September 21, 2012.

39. Chodzko-Zajko WJ, Proctor DN, et al; American College of Sports Medicine. American College of Sports Medicine position stand. Exercise and physical activity for older adults. Med Sci Sports Exerc. 2009; 41(7):1510-1530.

40. Sherrington C, Tiedemann A, Fairhall N, Close JC, Lord SR. Exercise to prevent falls in older adults: an updated meta-analysis and best practice recommendations. N S W Public Health Bull. 2011;22(3-4): $78-83$.
41. Granacher U, Muehlbauer T, Gruber M. A qualitative review of balance and strength performance in healthy older adults: impact for testing and training. J Aging Res. 2012;2012:708905.

42. Ammann BC, Knols RH, Baschung P, de Bie RA, de Bruin ED. Application of principles of exercise training in sub-acute and chronic stroke survivors: a systematic review. BMC Neurol. 2014;14:167.

43. StepMania.com [homepage on the Internet]. Available from: http:// www.stepmania.com. Accessed September 9, 2012.

44. de Bruin ED, Murer K. Effect of additional functional exercises on balance in elderly people. Clin Rehabil. 2007;21(2):112-121.

45. Lezak MD, Howiesen DB, Bigler ED, Tranel D. Neuropsychological Assessment. 5th ed. Oxford: Oxford University Press; 2012.

46. Baller G, Brand M, Kalbe E, Kessler J. Inventar zur Gedächtnisdiagnostik (IGD), Manual. Goettingen: Hogrefe; 2006.

47. Härting C, Markowitsch HJ, Neufeld H, Calabrese P, Deisinger K, Kessler J. WMS-R - Wechsler Gedächtnistest - revidierte Fassung. Bern: Huber; 2000.

48. Wechsler D. Wechsler Memory Scale-Revised (WMS-R) Manual. San Antonio: The Psychological Corporation, Harcourt Brace Jovanovich; 1987.

49. Gatterer G. Der Alters-Konzentrations-Test. 2nd ed. Goettingen: Hogrefe; 2008.

50. Wechsler D. Manual for the Wechsler Adult Intelligence Scale-Revised. New York: Psychological Corporation; 1981.

51. Jekauc D, Voelkle M, Wagner MO, Mewes N, Woll A. Reliability, validity, and measurement invariance of the German version of the physical activity enjoyment scale. J Pediatr Psychol. 2013;38(1):104-115.

52. Mullen SP, Olson EA, Phillips SM, et al. Measuring enjoyment of physical activity in older adults: invariance of the physical activity enjoyment scale (PACES) across groups and time. Int J Behav Nutr Phys Act. 2011;8:103.

53. Graves LE, Ridgers ND, Williams K, Stratton G, Atkinson G, Cable NT. The physiological cost and enjoyment of Wii Fit in adolescents, young adults, and older adults. J Phys Act Health. 2010;7(3):393-401.

54. Cohen J. Statistical Power Analysis for the Behavioral Sciences. 2nd ed. Hillsdale, NJ: Lawrence Erlbaum; 1988.

55. Deary IJ, Corley J, Gow AJ, et al. Age-associated cognitive decline. Br Med Bull. 2009;92:135-152.

56. Coubard OA, Duretz S, Lefebvre V, Lapalus P, Ferrufino L. Practice of contemporary dance improves cognitive flexibility in aging. Front Aging Neurosci. 2011;3:13.

57. Wilson, BA, Evans, JJ, Emslie H, Alderman N, Burgess P. The development of an ecologically valid test for assessing patients with dysexecutive syndrome. Neuropsychol Rehabil. 1998;8:213-228.

58. van het Reve E, de Bruin ED. Strength-balance supplemented with computerized cognitive training to improve dual task gait and divided attention in older adults: a multicenter randomized-controlled trial. BMC Geriatr. 2014;14:134.

59. Cai L, Chan JS, Yan JH, Peng K. Brain plasticity and motor practice in cognitive aging. Front Aging Neurosci. 2014;6:31.

60. Mirelman A, Herman T, Brozgol M, et al. Executive function and falls in older adults: new findings from a five-year prospective study link fall risk to cognition. PLoS One. 2012;7(6):e40297.

61. Hotting K, Schauenburg G, Roder B. Long-term effects of physical exercise on verbal learning and memory in middle-aged adults: results of a one-year follow-up study. Brain Sci. 2012;2(3):332-346.

62. Oswald WD, Gunzelmann T, Rupprecht R, Hagen B. Differential effects of single versus combined cognitive and physical training with older adults: the SimA study in a 5-year perspective. Eur J Ageing. 2006; 3:179-192.

63. Valenzuela M, Sachdev P. Can cognitive exercise prevent the onset of dementia? Systematic review of randomized clinical trials with longitudinal follow-up. Am J Geriatr Psychiatry. 2009;17(3):179-187.

64. Williamson JD, Espeland M, Kritchevsky SB, et al; LIFE Study Investigators. Changes in cognitive function in a randomized trial of physical activity: results of the lifestyle interventions and independence for elders pilot study. J Gerontol A Biol Sci Med Sci. 2009;64(6):688-694. 
65. Roig M, Nordbrandt S, Geertsen SS, Nielsen JB. The effects of cardiovascular exercise on human memory: a review with meta-analysis. Neurosci Biobehav Rev. 2013;37(8):1645-1666.

66. Liu-Ambrose T, Donaldson MG. Exercise and cognition in older adults: is there a role for resistance training programmes? Br J Sports Med. 2009;43(1):25-27.

67. Liu-Ambrose T, Nagamatsu LS, GrafP, Beattie BL, Ashe MC, Handy TC. Resistance training and executive functions: a 12-month randomized controlled trial. Arch Intern Med. 2010;170(2):170-178.

68. Cassilhas RC, Viana VA, Grassmann V, et al. The impact of resistance exercise on the cognitive function of the elderly. Med Sci Sports Exerc. 2007;39(8):1401-1407.
69. Marmeleira J. An examination of the mechanisms underlying the effects of physical activity on brain and cognition. Eur Rev Aging Phys Act. 2013; 10(2):83-94.

70. Etnier JL, Nowell PM, Landers DM, Sibley BA. A meta-regression to examine the relationship between aerobic fitness and cognitive performance. Brain Res Rev. 2006;52(1):119-130.

71. Chodzko-Zajko WJ, Schuler P, Solomon J, Heinl B, Ellis NR. The influence of physical fitness on automatic and effortful memory changes in aging. Int J Aging Hum Dev. 1992;35(4):265-285.

72. Zornetzer SF. Catecholamine system involvement in age-related memory dysfunction. Ann N Y Acad Sci. 1985;444:242-254.
Clinical Interventions in Aging

\section{Publish your work in this journal}

Clinical Interventions in Aging is an international, peer-reviewed journal focusing on evidence-based reports on the value or lack thereof of treatments intended to prevent or delay the onset of maladaptive correlates of aging in human beings. This journal is indexed on PubMed Central, MedLine,

\section{Dovepress}

CAS, Scopus and the Elsevier Bibliographic databases. The manuscript management system is completely online and includes a very quick and fair peer-review system, which is all easy to use. Visit http://www.dovepress. $\mathrm{com} /$ testimonials.php to read real quotes from published authors. 